\title{
COVID-19 pandemisinin genel cerrahi uzmanlık eğitimine etkisi
}

\author{
The effect of the COVID-19 pandemic on general surgery residency training \\ Osman Bozbıyık Metehan Gök \\ Ege Üniversitesi Tıp Fakültesi, Genel Cerrahi Anabilim Dalı, İzmir, Türkiye
}

Öz

Amaç: Koronavirüs (COVID-19) pandemisi elektif ameliyat sayıları üzerinde belirgin bir değişime neden olmuştur. Bu değişimin genel cerrahi uzmanlık eğitimini etkilemesi olasıdır. Fıtık cerrahisi genel cerrahi eğitiminin temel bir öğesidir. Bu çalışmanın amacı, pandemi dönemini bir yıl önceki aynı dönemle karşılaştırmak ve fıtık ameliyatı sayısındaki değişimden yola çıkarak pandeminin genel cerrahi uzmanlık eğitimi üzerindeki etkisini ortaya koymaktır.

Gereç ve Yöntem: Çalışmaya Nisan- Aralık 2019 (Kontrol grubu) ve Nisan- Aralık 2020 (Pandemi Grubu) tarihleri arasında yapılan elektif karın duvarı fıtığı ameliyatları dahil edildi. Elektronik hasta dosyaları retrospektif olarak taranarak ameliyat verileri elde edildi. İki grup toplam vaka sayısı, eğitim amacıyla uzmanlık öğrencileri tarafından yapılan ameliyat sayısı ve vaka sayılarının aylara göre dağılımı açısından karşılaştırıldı.

Bulgular: Çalışmaya toplam 273 ameliyat dahil edildi. Kliniğimizde 2019 yılı döneminde 212 fıtık ameliyatı, 2020 yılı döneminde 61 fıtık ameliyatı uygulanmıştı (p:0.001). Uzmanlık öğrencileri tarafından yapılan fıtık ameliyatı sayısı 2019 yılında 88 iken 2020 yılında 18'di (p:0,009). Pandemi döneminde toplam fıtık ameliyatı sayısındaki ve uzmanlık öğrencileri tarafından yapılan ameliyat sayısındaki azalma istatiksel olarak anlamlıydı. Pandemi öncesi dönemde vakaların \% 41,5'i, pandemi döneminde ise vakaların \% 29,5'i uzmanlık öğrencileri tarafından uygulanmıştı. Ameliyatların asistanlar tarafından yapılma oranında gruplar arasında istatiksel olarak anlamlı fark saptanmadı (p:0,103)

Sonuç: COVID-19 pandemisi döneminde elektif fıtık ameliyatı sayısı ve uzmanlık öğrencileri tarafından yapılan ameliyat sayısı azalmıştır. Cerrahi uygulamanın eğitimin önemli bir parçası olduğu göz önüne alındığında, vaka sayısındaki düşüş ve uzmanlık öğrencilerinin ameliyatlara katııımındaki azalma eğitimin kalitesini etkileyecektir. Bu sonuçlar, pandemi döneminde uzmanlık öğrencisi eğitiminin yeniden düzenlenmesi gerektiğini ortaya koymaktadır.

Anahtar Sözcükler: COVID-19 pandemisi, fıtık cerrahisi, tıp eğitimi.

\begin{abstract}
Aim: The coronavirus disease (COVID-19) pandemic has caused a significant change in the number of elective surgeries. This change is likely to affect general surgery residency training. Hernia surgery is an essential element of general surgery training. The aim of this study is to compare the pandemic period with the same period a year ago and to reveal the effect of the pandemic on the general surgery residency training, based on the change in the number of hernia operations.

Materials and Methods: Elective abdominal wall hernia surgeries performed between April-December 2019 (control group) and April-December 2020 (Pandemic Group) were included in the study. Surgical data were obtained from electronic patient files retrospectively. The two groups were compared in terms of the total number of cases, the number of surgeries performed by residents for educational purposes, and the distribution of cases by month.
\end{abstract}

\footnotetext{
Sorumlu yazar: Osman Bozbıyık

Ege Üniversitesi Tıp Fakültesi, Genel Cerrahi Anabilim Dalı,

İzmir, Türkiye

E-posta: bozbiyiko@gmail.com

Başvuru tarihi: 30.04.2021

Kabul tarihi: 26.05.2021
} 
Results: A total of 273 surgeries were included in the study. In our clinic, 212 hernia surgeries were performed in 2019 period and 61 hernia operations in 2020 period ( $p: 0.001$ ). The number of hernia surgeries performed by residents was 88 in 2019 and 18 in 2020 (p: 0.009). During the pandemic period, the decrease in the total number of hernia operations and the number of surgeries performed by residents was statistically significant. $41.5 \%$ of the cases in the pre-pandemic period and $29.5 \%$ of the cases during the pandemic period were applied by the residents. No statistically significant difference was found between the groups in the rate of operations performed by residents ( $p: 0.103)$

Conclusion: During the Covid 19 pandemic, the number of elective hernia surgeries and the number of surgeries performed by residents decreased. Considering that surgical practice is an important part of education, the decrease in the number of cases and the decrease in the participation of residents to the surgeries will affect the quality of education. These results reveal that residency student education should be reorganized during the pandemic period.

Keywords: COVID 19, Hernia surgery, medical education.

\section{AMAÇ}

Dünya sağlık örgütünün 11 Mart 2020 tarihinde COVID 19'u pandemi olarak ilan etti ve Türkiye'de de aynı gün ilk vaka görüldü (1). Pandemi ile birlikte sağlık sistemi belirgin bir değişime girmiş ve birçok ameliyat ertelenmiştir. Uluslararası meslek örgütleri, yayınladıkları kılavuzlarda elektif cerrahi işlemlerin mümkün olduğu kadar ertelenmesi gerektiğini savunmuştur (2). Sağlık sistemindeki bu değişim, eğitimin birçok alanında olduğu gibi genel cerrahi uzmanlık eğitimini de aksatmıştır (3).

Genel Cerrahi uzmanlık eğitiminde klinik yetkinliğin yanı sıra girişimsel yetkinlik de önemlidir. Bu nedenle uzmanlık öğrencileri yeterli sayıda cerrahi girişime hem dahil olmalı hem de pratik olarak uygulamalıdır. Sağlık Bakanlığı Tıpta Uzmanlık Kurulu tarafından yayınlanmış olan ve halen kullanımda olan Genel Cerrahi Çekirdek Eğitim Programına göre uzmanlık öğrencisinin girişimsel yetkinliği için dört düzey tanımlanmıştır. Birinci düzey yetkinlik "Girişimin nasıl yapıldığı konusunda bilgi sahibi olma ve bu konuda gerektiğinde açıklama yapabilme" düzeyini ifade ederken, dördüncü derece yetkinlik "Karmaşık olsun veya olmasın her olguda girişimi uygulayabilme" düzeyini ifade eder. Çekirdek eğitim programına göre tüm Genel Cerrahi uzmanlık öğrencilerinin fıtık cerrahisi konusunda dördüncü derece yeterliliğe sahip olmaları beklenmektedir (4). Genel cerrahi pratiğinde en fazla yapılan ameliyatlar arasında yer alması ve tüm kıdem basamaklarında yapılması nedeniyle de elektif fıtık ameliyatları Genel Cerrahi pratik eğitiminin en iyi göstergelerinden biridir(5). Bu çalışmanın amacı, Covid-19 pandemisinin Genel Cerrahi uzmanlık eğitimine olan etkisini, karın ön duvarı fıtığı ameliyat sayılarındaki değişimden yola çıkarak incelemektir.

\section{GEREÇ ve YÖNTEM}

$\mathrm{Bu}$ çalışma Ege Üniversitesi Tıbbi Araştırmalar Etik Kurul onayı (21-5T/101) ve T.C. Sağlık Bakanlığı'ndan gerekli izinler alındıktan sonra Ege Üniversitesi Tıp Fakültesi Hastanesi Genel Cerrahi Anabilim Dalı'nda gerçekleştirildi. Ameliyat kayıt sistemi verileri retrospektif olarak incelendi. Nisan 2020 ile Aralık 2020 arasında fıtık nedeniyle opere edilen hastalar ile bir önceki yılın aynı döneminde opere edilen hastalar çalışmaya dahil edildi. Hastalar pandemi grubu (1 Nisan 2020 ile 31 Aralık 2020 tarihleri arası) ve kontrol grubu olarak (1 Nisan 2019 ile 31 Aralık 2019 tarihleri arası) olarak iki gruba ayrıldı. Çalışmaya sadece elektif karın duvarı fıtığı nedeniyle ameliyat uygulanan hastalara ait ameliyat notları dahil edildi. Acil cerrahi uygulanan vakalar ve karın ön duvarı fıtığı dışındaki fıtıklar çalışmaya dahil edilmedi. Elektronik hasta dosyaları taranarak elde edilen veriler olgu rapor formlarına kaydedildi. İki grup; toplam vaka sayısı, eğitim amacıyla uzmanlık öğrencileri tarafından yapılan ameliyat sayısı ve vaka sayılarının aylara göre dağılımı açısından karşılaştırıldı.

Veriler IBM SPSS (Statistics for Windows, Version 25.0. Armonk, NY: IBM Corp.) programında analiz edildi. Gruplar arasındaki dağılımdaki farklılıklar, kategorik değişkenler için ki-kare testi kullanılarak hesaplandı. $P<0,05$ değeri istatistiksel olarak anlamlı kabul edildi.

\section{BULGULAR}

Çalışmaya toplam 273 karın ön duvarı fıtığı ameliyatı dahil edildi. Pandemi öncesi grubunda (2019 yılı) 212 fıtık ameliyatı uygulanmışken, pandemi dönemi grubunda (2020 yılı) uygulanan fıtık ameliyatı sayısı 61 olarak saptandı (Tablo-1). 
Pandemi döneminde elektif olarak uygulanan fıtık cerrahisi sayısı istatiksel olarak anlamlı şekilde azalmıştı ( $\mathrm{p}: 0,001)$. Ameliyat sayıları aylara göre değerlendirildiğinde pandemi grubunda Nisan, Mayıs ve Aralık 2020 dönemlerinde hiç vaka yapılmamıştı. Pandemi döneminde en çok vaka yapılan ay 14 elektif fıtık ameliyatı ile Eylül 2020 idi. Vakaların aylara göre dağılımı Şekil-1'de görülebilir.

Tablo-1. Pandemi öncesi ve sonrası gruplarının karşıllaştııılması.

\begin{tabular}{lccc}
\hline & Nisan- Aralık & Nisan- Aralık & $\mathbf{2 0 2 0}$ \\
& $\mathbf{2 0 1 9}$ & $\mathbf{p}$ \\
\hline Yaş (yıl) & $58,2 \pm 0,97$ & $58,15 \pm 2,04$ & \\
Cinsiyet (K/E) & $62 / 148$ & $13 / 48$ & \\
& & & \\
Toplam fıtık ameliyatı sayısı (n) & 212 & 61 & 0,001 \\
$\quad$ Inguinal /Femoral & 129 & 41 & 0,001 \\
$\quad$ Insizyonel & 62 & 16 & 0,014 \\
$\quad$ Umblikal/ Epigastrik & 21 & 4 & - \\
$\quad$ Toplam eğitim vakası sayısı (\%) & $\% 41,5$ & $\% 29,5$ & 0,103 \\
$\quad$ Toplam eğitim vakası sayısı (n) & 88 & 18 & 0,009 \\
$\quad$ Inguinal /Femoral & 56 & 15 & 0,008 \\
$\quad$ Insizyonel & 23 & 2 & 0,043 \\
$\quad$ Umblikal/ Epigastrik & 9 & 1 & - \\
Laparoskopik fıtık onarımı (n) & 62 & 26 & 0,072 \\
${ }^{*}$ Eğitim amacıyla uzmanlık öğrencisi tarafından uygulanan ameliyat sayısı & & \\
\hline
\end{tabular}

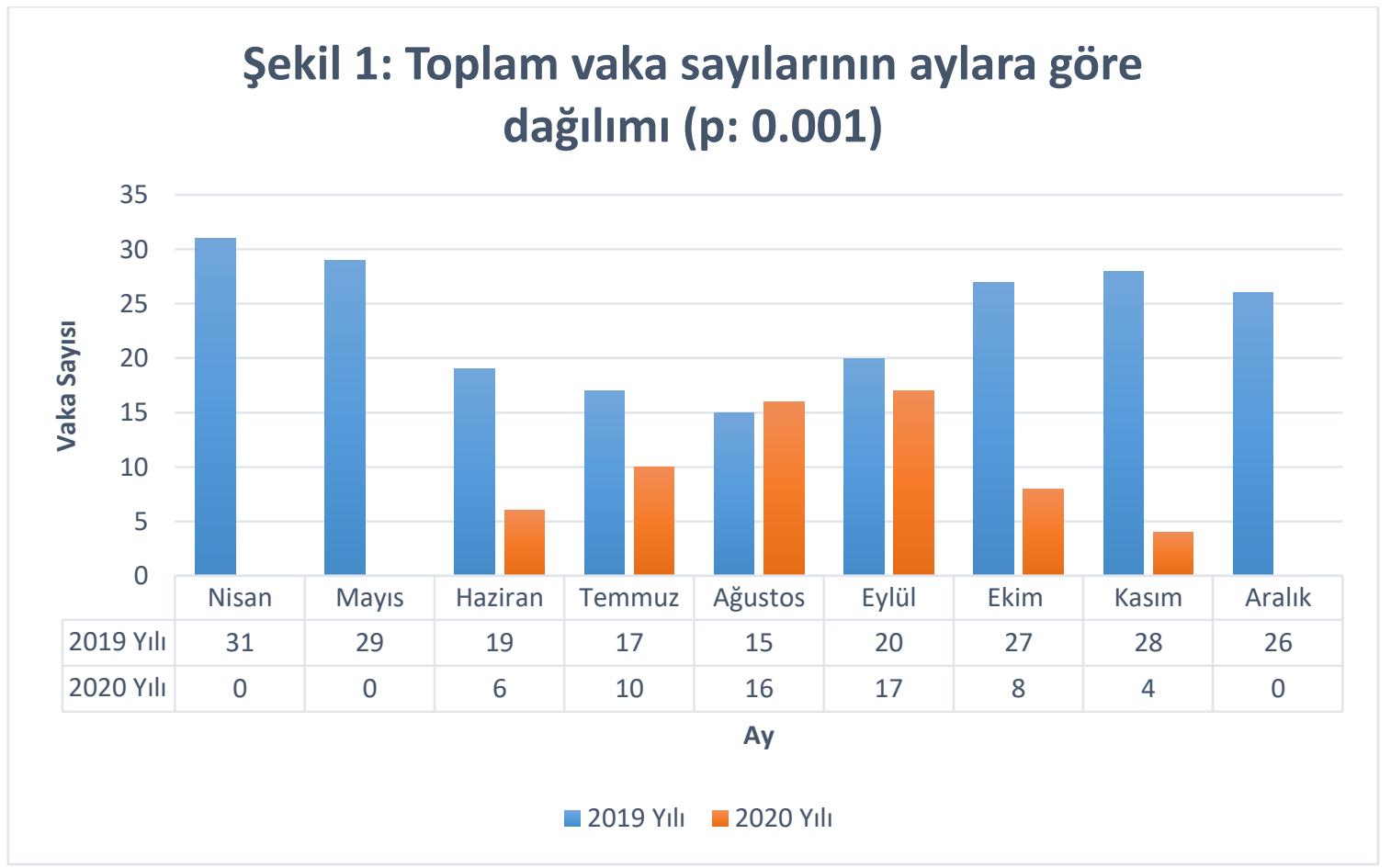

Şekil-1. Vakaların aylara göre dağılımı. 


\section{Şekil 2: Asistan vaka sayılarının aylara göre dağılımı (p: 0.009)}

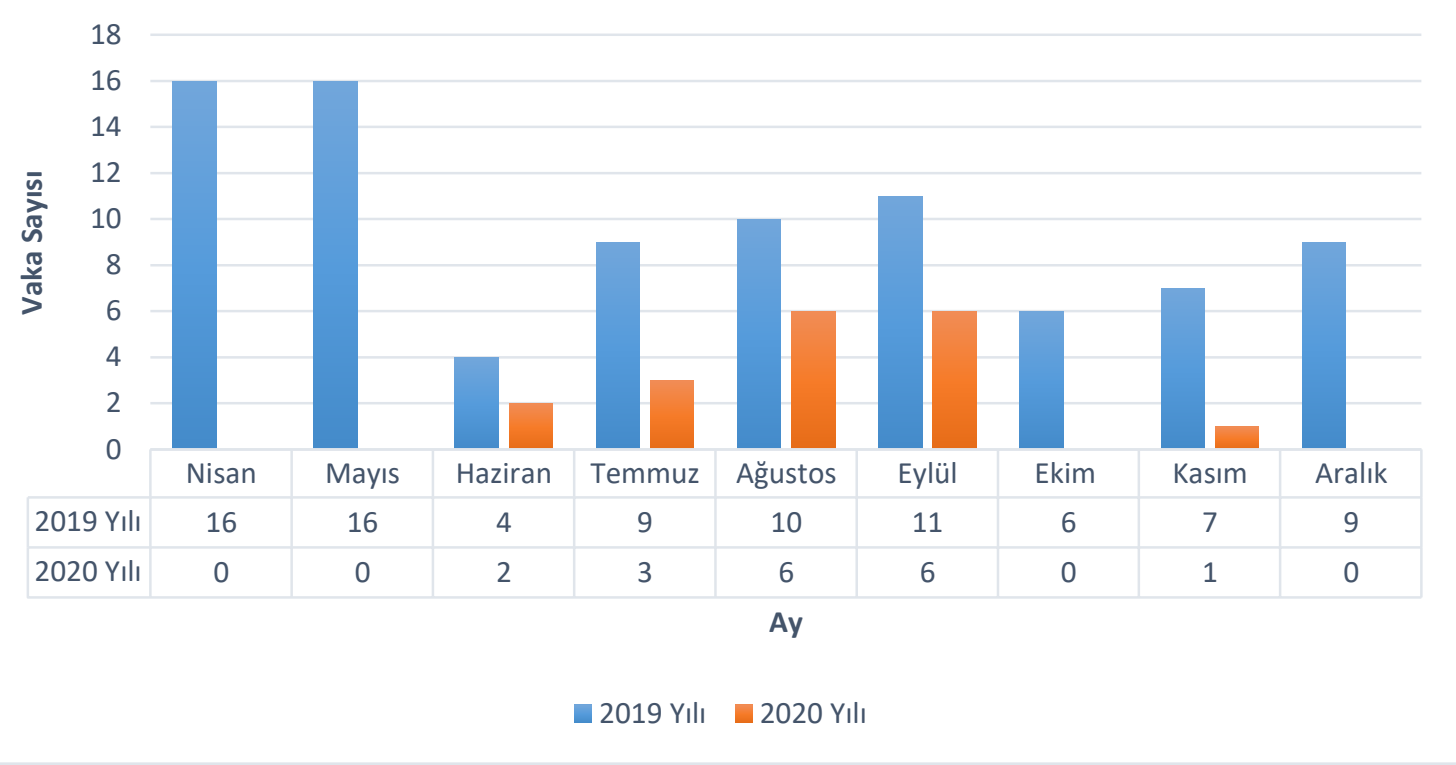

Şekil-2. Uzmanlık öğrencileri tarafından yapılan ameliyatların aylara göre dağıımı.

Uzmanlık öğrencileri tarafından yapılan fıtık ameliyatı sayısı 2019 yılında 88 iken 2020 yılında 18 'di. Pandemi döneminde uzmanlık öğrencileri tarafından yapılan ameliyat sayısı istatiksel olarak anlamlı şekilde azalmıştı (p:0,009). Uzmanlık öğrencileri tarafından yapılan ameliyatların aylara göre dağııımı Şekil-2'de görülebilir. 2019 yılında vakaların \%41,5'i; 2020 yılında vakaların \%29,5'i uzmanlık öğrencileri tarafından uygulanmıştı. Vakalarının uzmanlık öğrencileri tarafından yapılma oranında gruplar arasında istatiksel olarak anlamlı fark saptanmadı (p:0,103)

Fıtık tipleri açısından değerlendirildiğinde pandemi öncesi dönemde toplam 129 kasık fıtığı (inguinal/femoral) ameliyatı uygulanmışken, pandemi döneminde bu sayı 41'e gerilemişti (p:0,001). Eğitim amacıyla uzmanlık öğrencileri tarafından pandemi öncesi dönemde 56 kasık fıtığı ameliyatı uygulanmışken, pandemi döneminde bu sayı 15 olarak saptandı ( $p: 0,008)$. Toplam kasık fıı̆ğ ameliyatı sayısı ve uzmanlık öğrencileri tarafından uygulanan kasık fıtığı ameliyatı sayısı pandemi döneminde istatiksel olarak anlamlı şekilde azalmıştı. Inguinal fıtık ameliyatları değerlendirildiğinde, pandemi öncesi grubunda $62(\% 47,3)$ hastaya laparoskopik cerrahi uygulanmış iken, pandemi döneminde bu sayı $26(\% 63,4)$ olarak bulundu (p:0,072). Uzmanlık öğrencileri tarafından pandemi öncesi döneminde 28 laparoskopik vaka uygulanmışken, pandemi döneminde 11 vaka uygulanmıştı (p:0,117).

Benzer şekilde insizyonel fıtık ameliyatı sayısı pandemi öncesi 62 iken pandemi döneminde 16'ya gerilemişti (p:0,014). Eğitim amacıyla uzmanlık öğrencileri tarafından pandemi öncesi dönemde 23 insizyonel fıtık ameliyatı uygulanmışken, pandemi döneminde bu sayı 2 olarak saptandı ( $p: 0,043)$. Toplam insizyonel fıtık ameliyatı sayısı ve uzmanlık öğrencileri tarafından uygulanan insizyonel fitık ameliyatı sayısı pandemi döneminde istatiksel olarak anlamlı şekilde azalmıştı. Pandemi öncesi dönemde 21 umblikal/ epigastrik fıtık ameliyatı yapılmışken pandemi döneminde bu sayı 4'e gerilemişti. Pandemi öncesi dönemde bu vakaların 9'u uzmanlık öğrencileri tarafından yapılmışken pandemi döneminde sadece bir vaka uzmanlık öğrencileri tarafından yapılmıştı.

\section{TARTIŞMA}

Bu çalışmada, COVID-19 pandemisinin ilk dokuz aylık döneminde elektif olarak uygulanan karın ön duvar fıtığı ameliyatı sayısının ve bu ameliyatların uzmanlık öğrencileri tarafından uygulanma 
sayısının azaldığı ortaya konulmuştur. Genel Cerrahi eğitiminin temel taşlarından olan fıtık ameliyatı sayısındaki bu azalma pandemi döneminde Genel Cerrahi uzmanlık eğitiminin aksadığını objektif bir şekilde göstermiştir.

Cerrahi eğitiminin uygulamaya dayanması, ustaçırak ilişkisi içerisinde olması ve cerrahi eğitiminde daha fazla tecrübenin daha iyi sonuçla olan kuvvetli ilişkisi bilinmektedir (6). Genel cerrahi asistan eğitiminin temel unsurlarından biri olması nedeniyle fıtık cerrahisi ameliyatları örneklemimiz olarak seçilmiştir. Genel Cerrahi uzmanlık eğitiminde cerrahi teknik eğitiminde hedef, bir uzmanlık öğrencisinin standart bir ameliyatı bağımsız olarak yapabilmesidir. Uzmanlık öğrencisinin katıldığı ve yaptığı vaka sayıları yeterli eğitim aldığının belirleyicisi olmasa da cerrahi deneyim için önemli ve ölçülebilir bir göstergedir (7).

COVID-19, tüm cerrahi uzmanlık alanlarının eğitiminde olumsuz bir etkiye sahiptir ve bu dünya çapında hissedilmiştir. İrlanda'da yapılan bir çalışmada eğitimlerinin birinci yılında olan genel cerrahi uzmanlık öğrencilerinin ameliyat sayılarının \% 59,9 oranında, ikinci yılında olan uzmanlık öğrencilerinin ameliyat sayılarının ise \% 69,9 oranında düştüğü bildirilmiştir (8). Aziz ve ark'nın (9) ABD'de 1102 genel cerrahi uzmanlık öğrencisinde yaptığı anket çalışmasında pandemi döneminde cerrahi eğitimde belirgin bir düşüş olduğu bildirilmiştir. Benzer şekilde 23 Avrupa ülkesinden 327 Ortopedi uzmanlık öğrencisine yapılan anket çalışmasında, katılanların \%58,6'sı cerrahi eğitimin önemli ölçüde aksadığını belirtilmiştir. Katılımcıların \% 58,2'si eğitim hedeflerine ulaşılması ile ilgili kaygılı olduğunu,\% 25 'i ek bir yıllık eğitim intiyacı olduğunu ifade etmiştir (9). Beklendiği üzere tüm çalışmalar, bizim çalışmamıza benzer şekilde pandemi döneminde ameliyat hacminde ve deneyiminde belirgin bir azalma olduğunu bildirmiştir.

Türkiye'de ilk vaka 2020 yılı Mart ayında saptanmıştır. Pandeminin ilk pik dönemi olan Nisan ve Mayıs 2020 aylarında kliniğimizde hiç elektif fıtık ameliyatı yapılmamıştır. Özellikle pandeminin ilk pik döneminde, tüm dünyada elektif vakalarda belirgin bir azalma olduğu görülmektedir. Yılmaz ve ark (11). Türkiye genelinde 120 Genel Cerrahi uzmanlık öğrencisine yaptığı anket çalışmasında, OcakNisan 2020 dönemi bir önceki yılın aynı dönemi ile karşılaştırılmıştır. Bu çalışmada, pandemi döneminin ilk aylarında elektif ve acil fıtık, üst gastrointestinal, hepatobiliyer ve kolorektal cerrahi ameliyat sayılarında önemli bir düşüş olduğu, uzmanlık öğrencileri tarafından yapılan ortalama fıtık ameliyatı sayısının 9,67'den 0,76'ya düştüğü saptanmıştır. White ve ark (12). pandeminin erken döneminin, uzmanlık eğitimine etkilerini araştırdıkları çalışmalarında, 2020 yılının Nisan ayında Amerika Birleşik Devletleri'ndeki 84 uzmanlık eğitimi programı yöneticisine anket uygulamıştır. Tüm ABD'deki genel cerrahi eğitim programlarının \%33,6'sını içeren bu çalışmada kliniklerin tamamı eğitim programında yüz yüze olan aktivitelerin azaldığını ve \%95,2'si hastanede gündüz çalışan uzmanlık öğrencisi ve personel sayısının neredeyse yarı yarıya azaldığını bildirmişlerdir. İtalya'da pandeminin birinci ayında üroloji uzmanlık öğrencileriyle yapılan anket çalışmasında da COVID-19 pandemisinin erken döneminde, cerrahi eğitim faaliyetlerinde \%44,2 ila \% 62,1 azalma olduğu saptanmıştır (10). Tüm bu çalışmalar pandeminin ilk aylarında cerrahi eğitimin belirgin şekilde aksadığını göstermektedir. Bizim serimizde pandeminin kısmen kontrol altına alındığı yaz aylarında elektif vakalar tekrar alınmaya başlamış ancak pandeminin ikinci piki ile birlikte tekrar fıtık ameliyatı sayıları azalmıştır. Kliniğimizde Aralık 2020'de hiç elektif fıtık ameliyatı yapılmamıştır. Aşı uygulamaları umut vaat etse de pandeminin ne kadar süreceği ne zaman normal hayata dönüleceği henüz kimse tarafından net olarak bilinmemektedir. Bunu da göz önüne alarak eğitim sisteminin yeni şartlara göre oluşturulması gerektiği, yeni önlemler alınması gerektiği aşikardır. Pandemide olduğu gibi, toplam ameliyat hacminin azaldığı durumlarda cerrahi eğitimin aksamaması için alternatif eğitim yöntemleri kullanılmalıdır (11). Cerrahi asistanların teknik yeterliliğin gelişimini sağlamak için simülatör eğitim modelleri kullanılabilir (12). Ayrıca literatürde video tabanlı cerrahi becerileri eğitimlerinin kullanımı, çevrimiçi öğrenme modülleri ve sanal gerçeklik kullanılarak yapılacak eğitimlerin planlanması gibi alternatif eğitim yöntemlerinin kullanımının artırıması önerilmiştir $(13,14)$.

Literatürde ameliyat sayılarının azaldığını ve cerrahi eğitimin sekteye uğradığını gösteren çalışmaların çoğunluğu anket çalışmasıdır. Tüm anketlerde olduğu gibi, en ciddi şekilde etkilenenlerin ankete katılma olasılığı daha yüksek olacağından, bu çalışmalarda önyargı intimali önemli bir zayıflık olabilir (15). Bizim 
çalışmamız ise gerçek sayılar üzerinden, vakaların aylara göre dağılımını da içerecek şekilde veri sunmaktadır. Bunun yanı sıra bir yıl önce aynı dönem ile kıyaslama yapılarak, pandeminin etkisi objektif veriler ile tam olarak ortaya konulmuştur.

Sonuç olarak, COVID 19 pandemisinin etkisiyle elektif ameliyat sayıları ve uzmanlık öğrencileri tarafından yapılan ameliyat sayıları azalmıştır. Ameliyat sayısındaki ve deneyimdeki bu azalma Genel Cerrahi uzmanlık eğitimi kalitesini olumsuz yönde etkileyecektir. Bu çalışmanın sonuçları uzmanlık eğitim programlarının yeniden düzenlenmesi gerektiğini göstermektedir.

\section{Teşekkür}

Katkıları nedeniyle Prof Dr Sinan Ersin'e, Dr. Berk Göktepe'ye, Dr. Batuhan Demir'e teşekkür ediyoruz.

Çıkar Çatışması: Yazarlar çıkar çatışması beyan etmemişlerdir.

\section{Kaynaklar}

1. www.who.int [homepage on the Internet]. WHO - Coronavirus disease 2019 (COVID-19) Situation Report [updated 12 March 2020; cited 24 May 2021] Available from: 20200312-sitrep-52-covid-19.pdf (who.int)

2. Stabilini C, East B, Fortelny R, et al. European Hernia Society (EHS) guidance for the management of adult patients with a hernia during the COVID-19 pandemic. Hernia. 2020; 24 (5): 977-83.

3. Hope C, Reilly JJ, Griffiths G, Lund J, Humes D. The impact of COVID-19 on surgical training: a systematic review. Tech Coloproctol. 2021; 1:3.

4. tuk.saglik.gov.tr [homepage on the Internet]. Tıpta Umanlık Kurulu Genel Cerrahi Uzmanlık Eğitimi Çekirdek Müfredatı [cited 24 May 2021] Available from: v 2.4 dokümanları (saglik.gov.tr)

5. Zahiri HR, Park AE, Pugh CM, Vassiliou M, Voeller G. "See one, do one, teach one": inadequacies of current methods to train surgeons in hernia repair. Surg Endosc. 2015; 29 (10): 2867-72.

6. Elsey EJ, Griffiths G, Humes DJ, West J. Meta-analysis of operative experiences of general surgery trainees during training. Br J Surg. 2016; 104 (1): 22-33.

7. Maruthappu M, Duclos A, Lipsitz SR, Orgill D, Carty MJ. Surgical learning curves and operative efficiency: A cross-specialty observational study. BMJ Open. 2015; 5 (3): 1-6.

8. Joyce DP, Ryan D, Kavanagh DO, Traynor O, Tierney S. Impact of COVID-19 on operative experience of junior surgical trainees. Br J Surg. 2021; 108 (1): e33-e34.

9. Megaloikonomos PD, Thaler M, Igoumenou VG, et al. Impact of the COVID-19 pandemic on orthopaedic and trauma surgery training in Europe. Int Orthop. 2020; 44 (9): 1611-9.

10. Amparore D, Claps F, Cacciamani GE, et al. Impact of the COVID-19 pandemic on urology residency training in Italy. Minerva Urol e Nefrol. 2020; 72 (4): 505-9.

11. Ellison EC, Spanknebel K, Stain SC, et al. Impact of the COVID-19 Pandemic on Surgical Training and Learner Well-Being: Report of a Survey of General Surgery and Other Surgical Specialty Educators. J Am Coll Surg. 2020; 231 (6): 613-26.

12. Lu J, Cuff RF, Mansour MA. Simulation in surgical education. Am J Surg. 2021; 221 (3): 509-14.

13. Tuma F, Kamel MK, Shebrain S, Ghanem M, Blebea J. Alternatives surgical training approaches during COVID-19 pandemic. Ann Med Surg. 2021; 62: 253-7.

14. Ferriss JS, Rose S, Rungruang B, et al. Society of Gynecologic Oncology recommendations for fellowship education during the COVID-19 pandemic and beyond: Innovating programs to optimize trainee success. Gynecol Oncol. 2021; 160 (1): 271-8.

15. Christopher Ellison FACS E, Shabahang FACS MM. COVID-19 Pandemic and the Need for Disaster Planning in Surgical Education. Vol 232.; 2021. doi:10.1016/j.jamcollsurg.2020.10.008 